\title{
CHILD ABUSE IN IGBOLAND OF NIGERIA: EXPLANATIONS, PSYCHOLOGICAL IMPLICATIONS AND ENDING THE SILENCE
}

\author{
Ugwuanyi Benedict CHIDI, Zbigniew FORMELLA ${ }^{2}$ \\ Università Pontificia Salesiana \\ formella@ unisal.it
}

Key words: child abuse; Igboland; family; prevention;

\section{Introduction}

Child abuse is as old as man. It happens in different parts of the world. Some countries, cultures and governments are advanced in handling the problem, while others are just waking up to the reality. However, that does not mean that children are not harmed in those societies where the government is still silent. Even though the statistics data from United Nations Children's Fund (UNICEF) and World Health Organization (WHO) vary from city and city, from country to country, and from year to year, what is not in dispute is that child abuse is an international problem. Children are abused regardless of the culture, society, or socio-demographics of the individual child (Bekerian \& Levy, 2012, 68).

In the past fifty years, the issue of child abuse was not a topic of discussion in Igboland of Nigeria. Though the Igbos are noted for their love for children. It is interesting to note that some parents and teachers in disciplining the children go to the extreme and put the children in harmful situations. Hence, the devastating effects of child abuse have called the attention of psychologist, scholars and government. Today it is becoming an important issue of awareness. To achieve this uphill task, all hands need to be on deck to tackle the serious nature of this ugly phenomenon. This leads to a serious discussion on the prevention of child abuse.

Preventing child abuse before it occurs in the family, school or in the society is the fundamental goal of reducing the occurrence of child abuse. In fact, most authors, psychologist and experts in the file of child abuse and maltreatment agree that, policies, strategies and programmes for preventing child abuse must aim on preventing child abuse before it happens. To achieve this goal, there are programmes that aims in improving the parenting skills. These programmes are designed to help parents develop a positive,

\footnotetext{
${ }^{2}$ Università Pontificia Salesiana, Roma.
} 
healthy and secure attachment with their children (Miller-Perrin \& Perrin, 2007, 104). If parents understand the child's development they will know why the child comports or acts in certain manners.

\section{Definition and Concept of Child Abuse}

Child abuse is made up of two words and it will be important that we first understand the meaning of the two words and then make an attempt in defining child abuse.

The definition of a child varies from one school of thought to the other. The reason is that some writers, intellectuals and professors are sometimes influenced by their culture and religious beliefs. Therefore, this constitutes a big problem in determining when childhood begins and end. This article retains that a child is a person experiencing the period of development from infancy to puberty (Rathus, 2014, 4).

Again, there is an on-going debate on the definition of abuse. Nevertheless, many authors prefer to use this definition. Abuse is treating another person in a harmful, injurious, or offensive way (Davis, 2011, 65).

Having clarified the two words, let us try to define the term child abuse. It is worth mentioning that people's environment and cultural background determines the way they perceive the issue of child abuse. This makes the issue to be a bit complicated. The complexity of child abuse has drawn the attention of different scholars from different areas of life. It is of interest to note that disciplines like psychology, sociology, psychiatry, paediatrics, education, social work, law enforcement have attempted to give a definition of child abuse based on their background and orientation.

Notwithstanding the disagreement on the definition of child abuse, we would like to go with this definition. Child abuse is any form of physical, mental injury, or sexual abuse or exploitation, negligent treatment, maltreatment, or cruelty towards a child by a parent or other adult (including all those that are responsible for the child's welfare), causing significant harm to its victim (Colman, 2009, 129). One thing that is common in most of the definitions of child abuse is that they talk about the child, the person that abuses the child and the damage that was inflicted on the child who is considered as a casualty.

This definition brings to light what some children are passing through in Igboland. It is unfortunate that when an African (Nigeria) child and in particular reference to Igbo children is mentioned, what comes to some people's mind is poverty, sickness, etc., forgetting the aspect of child abuse. Unfortunately, child abuse exist in Igboland of Nigeria and seems to be receiving little attention from the government, scholars and few psychologist around the town. 
In Igbo society, the child is loved, esteemed, valued, and treasured. They cherish a child more than having money. In fact, for the Igbos, nothing is comparable to a child. This is reflected in many personal names of the Igbo, such as: Ifeyinwa, there's nothing like a child, Nwakaego, a child is better than wealth, Nwabueze, the child is king and 'Nwabu-uwa', meaning a child is all the world to me. Children as seen as cherished assets of the family. In the Igbo man's world, numerous proverbs and sayings are continually used in everyday situations to describe the joys of having children and the sorrows of childlessness. This shows the importance of children in marriage and indeed among the Igbo (Okuma, 2009, 125).

Since the child is regarded as one of the greatest valuable asset in Igboland, the parents, adults and the Igbo society take training of their children very seriously. In the families, parents discipline the children to straighten them up while in the school's children are disciplined by their teachers. Normally, the teachers discipline the students by flogging them. Sometimes, the children are asked to kneel down on the floor on their bare knees. Again, there are cases where these children are whipped on their buttocks, backs and hands.

It is true that in Igbo society, the parents pay attention to the discipline of the children. Unfortunately, many Igbo parents do not know the difference between child training, child discipline and child abuse. It is natural for a child to expect a correction from the parents when he or she fails an assignment or but the contrary is the case with regards to abuse. Child abuse is unpredictable and injures the child. In fact, there's a big difference between discipline and abuse.

Discipline is given in a direct response to a person's actions. In this case there's an identifiable cause to discipline the child. The goal of discipline is altered behaviour and a change in the way a person responds to life. Discipline is an act of love by the parent or anyone in charge of the child and it is rooted in desire for the child to be the best he or she can be. Abuse, on the other hand, is frequently unrelated to a child's behaviour. The innocent action of the child who is considered as a victim may trigger a violent response in an abuse. The person who is abusive has an inner predisposition to abuse. Abuse seeks to do a victim harm and is based on manipulative and control of power (Stanley, 1994, 61).

In Igbo society, some parents educate their children with strict rules. They punish their children at any slightest mistake without hearing from them. Sometimes, parents slap their children when they want to explain the reason why they did not carry out the instructions given to them. In a nutshell, the Igbo parents believe in this famous proverb, 'spare the rod spoil the child'. This proverb means "if a person is not punished for doing wrong, more often than not, that person ends up spoiled" (Berina, 2010, 16). 
However, some parents and teachers go to the extreme and put the children in harmful situation.

\section{Types of child abuse}

Children experience different forms of child abuse in different situations. In fact, there are different types of abuses but this article retains that there are four types of abuses and they include the following; physical abuse, sexual abuse, psychological abuse and child neglect.

Physical abuse: Defining physical abuse can be very challenging and demanding because some cultural beliefs, values and environment tend to spur the use of physical punishments by parents, caregivers and elder siblings towards the children. The Diagnostic and Statistical Manual of Mental Disorder DSM-5 describes child physical abuse as "a nonaccidental physical injury to a child- ranging from minor bruises to severe fractures or death-occurring as a result of punching, beating, kicking, biting, shaking, throwing, choking, hitting (with a hand, stick, strap, or other object), burning, or any other method that is inflicted by a parent, caregiver, or other individual who has responsibility for the child. Such injury is considered abuse regardless of whether the caregiver intended to hurt the child. Physical discipline, such as spanking and paddling, is not considered abuse as long as it is reasonable and causes no bodily injury to the child" (American Psychiatric Association, 2013, 717).

Unlike the other types of child abuse, the signs and symptoms of physical abuse of a child is easily detected because of the marks on the body and the appearance of the child in question. In some cases, it is obvious to see cigarette burns on the child's palms, soles of feet or abdomen; bruises on the face, upper arms, buttocks, thighs or lower back, punch and slap marks, broken bones, bruises, black eyes, injuries and signs that the child does not receive medical care for the injuries.

In Igboland, parents believe that disciplining a child will help the child to become a good and responsible person. Their aim in disciplining them is for their child to be stable and be good ambassadors wherever they find themselves in the future. Regrettably, they sometimes cross the margin between discipline and enter into the territory of abuse.

Sexual abuse: "Child sexual abuse encompasses any sexual act involving a child that is intended to provide sexual gratification to a parent, caregiver, or other individual who has responsibility for the child. Sexual abuse includes activities such as fondling a child's genitals, penetration, incest, rape, sodomy, and indecent exposure. Sexual abuse also includes noncontact exploitation of a child by a parent or caregiver-for example, forcing, tricking, enticing, threatening, or pressuring a child to participate in 
acts for the sexual gratification of others, without direct physical contact between child and abuser" (American Psychiatric Association, 2013, 717).

Literally speaking, the possible effects of child sexual abuse include pregnancy and sexually transmitted infection. In some cases, stains of blood on the legs or the child's underwear. Some children after the ugly experience, find it difficult to walk, sit down or urinate. Some have pain or itching, in the genital area or bite marks to thighs and genital area.

In Igboland, some average or rich families employ the children from poor families as domestic helpers. It's unfortunate that some of these children are victims of these very ugly phenomenon. When they cannot bear it any longer, they ran out of the house and end up in the streets where they are exposed to commercial sexual exploitation. The majority of the children that run out of the house are girls and they end up as hawkers in other to survive. Again, some of these children especially the girls among them are sexually abused by individuals who are old enough to be their parents.

Psychological abuse: psychological abuse is a concerted attack on a child's development of self and social competence, a pattern of psychically destructive behaviour which consists of five forms: rejecting, isolating, terrorizing, ignoring and corrupting (Garbarino, Gutman and Seeley cit. in. Kay, 2003, 33). In 2013, DSM-5 presented a classical definition of child psychological abuse stating that "Child psychology abuse is nonaccidental verbal or symbolic acts by a child's parent or caregiver that result, or have reasonable potential to result, in significant psychological harm to the child" (American Psychiatric Association, 2013, 719).

The sign of child psychological abuse seems to be more difficult to detect than other types of abuse. Whereas the physical and sexual abuses involve harming or marring the body of the child, in psychological abuse the child's spirit is being touched and harmed. Sometimes it may include the deprivation of love, stimulation and security. The possible signs of psychological abuse are most likely found when a child begins to display loss of self-confidence or self-esteem, depression, social withdrawal or loss of interest/enthusiasm for things that a child previously enjoyed etc.

In Igboland, there is mutual respect for each other but a lot has to with respect for parents and elders. This respect for parents, adults and those in authority can be seen in the way children listen to them and carry out the daily activities as directed by them. On the contrary, some parents in disciplining their children go to the extreme by shouting, scolding, insulting their children without paying attention to the psychological effect. These are some of the common insulting words that parents use often; Onye' ala-Mad person, Onye ime- ezi- Bush person, Onye Nzuzu-Stupid person etc. These words have an effect on the psychological development of the child. 
Child Neglect: "Child neglect is defined as any confirmed or suspected egregious act or omission by a child's parent or other caregiver that deprives the child of basic age-appropriate needs and thereby results, or has reasonable potential to result, in physical or psychological harm to the child. Child neglect encompasses abandonment; lack of appropriate supervision; failure to attend to necessary emotional or psychological needs; and failure to provide necessary education, medical care, nourishment, shelter, and/ or clothing" (American Psychiatric Association, 2013,718).

Child neglect in Igboland come from parents and people who are responsible for the child's well-being. In Igboland, those who are responsible for the children includes the parents, teachers, relatives and neighbours of the child in question. Neglect can be seen in form of malnutrition, poor living conditions, inadequate health care, lack of adequate clothing etc.

In the past in Igboland, the man goes out to work while the woman stays at home and takes care of the children. Presently, the situation is no longer the same. Both the man of the house and the woman go to work in their respective areas of work. Sometimes, they do not provide the child with his or her basic needs. It is unfortunate to state that some parents in Igboland are not aware that neglect leads to significant poor psychological and educational outcomes for their children. Hence, we can summarise this point by stating that child neglect is the failure of the parent or the caregiver to provide the basic amenities for the child which comprises of physical neglect, medical neglect, educational neglect, supervisory neglect, and emotional neglect.

\subsection{Major causes of child abuse}

Child abuse happens in different homes in Nigeria- Igboland where the risk factors tend to be high. Child abuse can be caused by a number of factors. However, this article will focus attention on few major causes of child abuse. Knowledge of the causes of child abuses will help parents and those responsible for children in Igboland to know when something is going wrong with the child and equally to know the boundaries between child discipline and child abuse.

Poverty and stress: Poverty is "a lack of resources required to meet an individual's or a family's needs" (Ranyard, 2017, 422). Poverty most of the time helps in building an unhealthy home which hinders the development of a child. In fact, it retards every sphere of social, physical, emotional and psychological life of a child.

In an environment where poverty has become a culture of its own, parents and adults are likely to become overwhelmed by stress. We are not trying to prove the fact that many parents under a great deal of stress abuse their children. Instead, we want to reiterate the point that the stresses of 
poverty lead to child abuse. Still on this point, we would like to state that stress is something that is subjective. What someone considers as a stressful activity or phenomenon may not be the same for the other person. Nonetheless, the bottom line is that some parents do not know how to cope when they are stressed out and as such they pass their anxiety and stress on to their children.

Serious marital problems: There are so many reasons which causes serious family instability, take for instance; economic situation, extra marital affairs, lack of trust, religion, infertility of the wife etc. These factors can lead to a separation of the couples or divorce. It is interesting to note that children at this point bears the consequences of the unresolved conflicts of their parents. "Family circumstances, most notably conflict and marital violence, also have a causal connection to child maltreatment. Tragically, not only do marital violence and family turmoil frighten and disturb children in a direct manner, but the resulting fallout from these events, ranging from changes in financial status and living quarters to loss of family unity and safety prolongs the stress and thus the harmful impact on children's development" (Mash \& Wolfe, 2016, 417).

Unwanted pregnancy: When a child is not accepted by the parents or one of them, there is the possibility of the child experiencing poor parenting and even child abuse. This goes contrary to the attachment theory of Mary Ainsworth and John Bowlby in the world of psychology. "The parent's sensitivity to those cues and signals is an important pathway to a secure parent-child attachment and the child's subsequent competence and wellbeing. Sensitivity includes identifying, interpreting, and responding appropriately and consistently to the baby's cues" (Sameroff, McDonough \& Rosenblum, 2004, 225).

Unfortunately, when some mothers give birth to a baby that she did not want at the time of conception, they fail in the aspect of mother-child relationship especially in terms of their social, emotional and cognitive development. Most of the time, they abuse these innocent children.

Unemployment: Globalization has changed most of the lifestyle of the ordinary man and woman in the world. In fact, the impact of globalization has tremendous effects on the masses. We have both the positive and negative effect. However, unemployment is considered as a fruit of globalization and many couples are searching for jobs because they need to maintain and sustain their families. "Unemployment per se, is probably not the variable that directly elicits abusive behaviour. It appears to be the concomitant stresses, or functions of unemployment, which lead to abusive acts. Several reasons are proposed in the literature. Unemployment may be associated with financial strain; an unemployed father is home for longer 
periods of time, thereby increasing the possibility for conflict between father and child" (Childs \& Melton, 2012, 315).

\subsection{Attitude that encourages Child Abuse in Igboland of Nigeria}

There are different behaviours that are being put up by a good number of people at different times and different places, intentionally or unintentionally. People can sometimes conceal their attitudes or even be unaware of their attitudes. In Igboland, there are certain attitudes which encourages child abuse. Some of these attitudes have lasted for a long time in the society without any criticism and as such it seems like a tradition. Below are some of the attitudes that is consistent in the Igbo society.

Acceptance of the use of physical punishment: The term physical punishment is associated with the phrases such as corporal punishment, physical punishment and physical discipline. These phrases are used interchangeably and they "refer to the correction or punishment of a child's behaviour through the deliberate or ill-considered infliction of body pain, however minor or intense" (Freeman, 2014, 158).

In Igbo society, some parents still uphold that physical punishment is one of the means of disciplining a child. It is a popular opinion among some parents that it is necessary to smack a naughty child. It is true that these physical punishments are carried out by Igbo parents with the intention of correcting their children but the problem at stake is that sometimes it ends up inflicting the child with a serious injury. Sometimes, the parents that were seen as not punishing their children physically are considered as weak parents. In fact, some believe that they are spoiling their children.

"The Igbo family, and, in general, the Nigerian family, discourages and prohibits acts likely to bring disrepute to the family. As a result, severe physical punishment is meted out to the young offenders in the hope that this will serve as a deterrent" (Offohia \& Sadiku, 1996, 79). It is obvious that physical punishment aggravates and leads to child abuse. Though it is a welcome attitude by some parents in Igboland. However, that does not justify the means.

Acceptance of child hawking: Poverty is a notable factor that has contributed strongly to child hawking in Igboland. In fact, "due to the poor socio-economic status of some parents, they send their children into hawking in order to make both ends meet. Children are now the ones making money for their school fees and their welfare. When a child goes to hawk food items early in the morning before going to school or as soon as he comes back to school, it seriously affects his academics. These are the children that come to school weak and tired and in most cases they are always the ones dozing in the class. In such cases education becomes a ceremonial instead of being a 
right. A child's human dignity is affected when he is subjected to such treatment" (Emezue, Kosch \&Kangel, 2014, 98).

In Igbo society, it is worrisome and alarming that some parents accept the idea of sending their children especially the girls to hawk. Although one can argue that the economic factor and many other factors like war, illiteracy, religion, poor family planning can induce parents into involving their children into this very act. However, this despicable phenomenon and experience has a horrendous effect on the developmental process of the child.

Child hawking has many consequences for the child. It has a physical, psychological and social consequence for the child. Apart from the stress, fatigue, depression, anger that the child undergoes, it equally exposes the child to unwanted pregnancies, prostitution, smoking, robbery, truancy and poor academic performance.

Acceptance of child or early marriage: "Child marriage, also known as early/forced marriage is the practice of coercing, deceiving or forcibly giving out a child into marriage at such an age when he or she is incapable of understanding the nature of marriage, as to give free, full or informed consent to it and is physically- anatomically, physiologically and psychologically- emotionally, spiritually and mentally, immature for marriage" (Ukwuoma, 2014, 10).

It is ludicrous that their minor daughters are exposed to early pregnancy and its problems. Most times, "decisions affecting the girl in the marriage is usually taken without the girl's inputs. She stands the risks of domestic violence by her husband since she does not have the maturity to handle the challenges of marriage. She is exposed to high risks and hazards related to early pregnancy and childbearing and may be abandoned by the purported husband and treated as a social outcast even among her peers. In the state of her frustrations, hopelessness and helplessness, death may be the nearest acceptable option if she is not given the desired attention and rehabilitated within a reasonable time" (Ukwuoma, 2014, 68).

Acceptance of child as house help or nanny: It is really a pity that in Igboland children are employed as house helps and nannies. Children are supposed to be loved by their parents. They are supposed to be taken care by their parents but unfortunately, the reverse is the case. The question remains, who is a house help? A house help is regarded as someone who works for the person, to perform common household chores. A house help is a person who lives with you to work for you, and assist with washing dishes, clothes and washing other things. A house help is not a member of the nuclear family (Tambo, 2014, 229).

In Igboland, some families especially the rich ones employ children from the villages to take care of their children in the urban areas. "Poverty 
makes the low families in the rural villages send their young children aged anything between 7 and 18 to serve elite urban families. The employing families on the other hand feel that since they are providing these children with some of the facilities their parents cannot afford in the village, such children are privileged to be house helps. So if they are made to work long hours and are sexually molested by their employers and their children, nobody cares" (Eya, 2002, 66).

When a child grows in this type of environment, the child tends to be over laboured, under-nourished and even under-developed. It is obvious that these children especially the girls end up being victims of child abuse. "The majority of victims, no doubt fall within the category of children in need of special protection such as street children; orphans including those of HIV and AIDS; abandoned and neglected children and other children in distress. It is worth noting that girls working as domestic workers in our big cities are often exposed to sexual exploitation and abuse by their masters and other male members of the family that they serve" (Danpullo, 2008, 56). When a child undergoes all these abuses, most of the time it conveys a strong message in their minds that they are worthless and unloved.

\section{Child abuse prevention in Igboland of Nigeria}

In Igboland, often we hear cases of child abuse and this preoccupies any sane person in the society. The vision of Igbo people should be to see their children in safe and stable families. It is also important to raise awareness about the role that every single person in the Igbo community play in keeping the children safe in the families, schools and society. Children need to grow in a healthy environment.

Family: As already stated before, the family is the foundation of Igbo society. Family plays a vital role in the upbringing of a child. The family nurtures the child so that he or she will be balanced psychologically and in every aspect of their well-being. The child's relationship within the family in Igboland is not limited only to his parents and sibling but extends to friends, grandparents, aunts, uncles, and other members of the extended family.

Unfortunately, some of these children come from poor families and as such experience child neglect or other type of child abuse. Again, regrettably the poor families where the children are living cannot afford three square meals a day. Imagining what a child in Igboland will be experiencing by living in a family that has constant shortage of food.

Strengthening economic support for poor families will go a long way in reducing child abuse in these families. "Policies that strengthen household financial security by improving the socio-economic conditions of families tend to have largest impact on reducing child abuse by improving parent's ability to satisfy children's basic needs" (Hinds \& Giardino, 2017, 136). 
Again, "the strengthening of families is based on family economic success which focuses on helping individuals improve self- sufficiency through expanded opportunities to work, earn a living wage that provides for the basic needs of the family and build assets that grow the family over time, such as home ownership and retirement accounts; family support system which stress on building appropriate and adequate system of support for healthy family development that encompasses: health care, child care, education, and other essential components of strong families" (Mokomane, 2014, 173). When this is achieved, it will help the poor families especially the parents to cope more effectively with the child's pressure and actions and equally reducing the destructive elements in the family and society that contributes to child abuse.

Schools: The importance of school in the lives of children cannot be over-emphasized. Apart from the fact that it is a formal education which prepares children for the future, it equally helps them to interact with their peers and teachers. "Children spend a large proportion of their working hours in school, and interact with many other social persons there to play a range of social roles. The school contains many microsystems within which children engage with others who are often of great emotional and practical significance for them. It is also perhaps the part of their childhood where there are strong macrosystem influences focusing most obviously and explicitly on children: the culture demands that children should have formal education, requires them to learn specific things in school" (Meadows, 2010, 206).

Child abuse is common in the schools in Igboland. Most of the time, children are considered as domestic workers. "A form of child abuses and labor prevalent in school settings in developing countries involves students doing domestic chores for teachers during school hours and at community schools that provide on-site housing for teachers. The domestic chores include cooking and cleaning, making the teacher's bed, buying groceries for teachers, fetching water and firewood" (Clauss-Ehlers, 2010, 194).

"Schools and educational facilities are the most trusted of institutions. Society expects schools not only to educate children but also to protect them and prevent violence against them. With regards to child abuse prevention, schools should provide policies, procedures, and supervision for employees so that opportunity for abusive is limited. Again, children should be taught safety curricula that encompass what they should and should not allow, who to tell if they are being, and how to avoid victimization. Personnel in schools and child care should be taught to watch for signs of possible neglect and abuse" (Hirschy \& Wilkinson, 2010, 60).

It is the role of the teachers to teach the children (students) to be aware of dangers of abuse. This will help them to understand the characters of a 
potential perpetrator and at the same time to know how to protect oneself. Again, "the school staff should participate in training which develops understanding in the signs and symptoms of child abuse. However, it is essential that sufficient discussion of the issues around child protection takes place in school so that all staff develop a clear view of their responsibilities. Awareness of the signs of child abuse needs to be well established neither are potential signs missed nor innocent factors misinterpreted" (Farrell, 2001, 40).

Society: For a relatively long time Igbo society has demonstrated a capacity to shape the direction of change within its boundaries. In fact, they have demonstrated ingenuity in their creative adaptability to their environment and in their view with regards to the right of a child (Chuku, cit. in. Falola \& Njoku, 2016, 46).

The problem of child abuse is a remarkable and an outstanding problem facing the Igbo society. The impact of child abuse does not end only with the effects it has on the abused children. Rather, it negatively affects the society directly or indirectly in different ways. In Igboland, every aspect of child abuse affects not only the abused child but equally the family, the people around and the society. The effects on the people includes the emotional stress, financial strain, work, social relationships, etc. If care is not taken, the individual who is regarded as the abuser may tend to transmit this ugly character to other individuals and thus constituting a big nuisance to the society.

To this effect, Igbo society considers public awareness as an important tool in preventing child abuse. Public awareness is an important aspect of preventing child abuse and at the same time improving the quality of life of the child in the community. One good thing about public awareness is that it teaches the masses what to do and at how to avoid child abuses.

Another approach to the prevention of child abuse in the society is that of educating the public about the problem through the mass media campaigns. Such campaigns employ public service announcements on radio and television; in newspapers, magazines, brochures, posters and billboards. The rationale behind this approach is that increasing knowledge and awareness about the problem of child abuse will result in lower levels of abuse. The awareness created in the society may also indirectly reduce rates of abuse as professionals and people begin to recognise the signs and symptoms of child abuse and also begin reporting suspected abuse to authorities (Miller-perrin \& Perrin, 2012, 90).

If the Igbo society continues to create and promote awareness to the people concerning the prevalence of child abuse, it will definitely help to reduce the cases of abuses. Again, the society can equally organise a prevention programs against child abuse. The sole aim of organising 
prevention programs is purely to prevent child abuse before it occurs. The programme teaches the parents on how to handle difficulties in the family. Prevention programs are usually educative, supportive and therapeutic. However, there are programs which are meant for children and sometimes it focuses towards one type of child abuse.

\section{Conclusion}

The issue of child abuse in Igboland as a societal problem needs a collective effort. The Igbo people need to work together to help strengthen and support families so as to prevent abuses on children from occurring. However, we need to ask one fundamental question, can we stop child abuse before it ever starts? Sadly, we cannot turn back the clock for those children already harmed by child abuse of various types. For such children, ongoing intensive efforts are necessary to ameliorate the effects of their maltreatment and abuses, to protect them from future harm, and to give them the best chance of developing into whole and healthy functioning adults. However, for those child not yet abused, we can prevent child abuse before it before it happens and as such avert the damaging effect (Guterman, 2001, 3).

Again, we need to ask another question, what can we do to stop child abuse and protect children in Igboland? "Each and every individual in the society has moral responsibility for protection of child abuse. There should be effort from every corner of the society to stop child abuse at all levels though responsibility of parents seem to be heavier as it is a question of safety and security of their own children who are also future of our country" (Padhi, 2013, 33). Now is the time to break the silence on child abuse in Igboland of Nigeria because it has lasting effect on the child's personality, mental health, physical health, social behaviour, social skills and at times prevents the child from committing suicide.

\section{References:}

AMERICAN PSYCHIATRIC ASSOCIATION. (2013). Diagnostic and Statistical Manual of Mental Disorder. (5th ed). American Psychiatric Publishing: Washington, DC.

BEKERIAN, D., \& LEVEY, A. (2012). Applied Psychology: Putting Theory Into Practice. New York: Oxford University Press.

BERINA, R. (2010). The Heart. Mill City Press: Minneapolis.

CHILDS, A., \& MELTON, G. (2012). Rural Psychology. Plenum Press: New York.

CLAUSS-EHLERS, C. (2010). Encyclopedia of Cross-Cultural School Psychology. Springer: New Jersey. 
COLMAN, A. (2009). Oxford Dictionary of Psychology. Oxford University Press: New York.

DANPULLO, R. (2008). The Socio- legal Perspective of Child Protection in Cameroon. Presses Universitaires D’Afrique: Yaoundé.

DAVIS, R. (2011). Animals, Diseases, and Human Health: Shaping Our Lives Now and in the Future. $\quad$ Praeger: California.

EMEZUE, G., KOSCH, I., \& KANGEL, M. (2014). Justice and Human Dignity in Africa. Hpc books: New York.

EYA, R. (2002). Child Abuse and Neglect. Sages Publications : Enugu.

FALOLA, T., \& NJOKU, R. (2016). Igbo in the Atlantic World: African Origins and Diasporic Destinations. Indiana University Press: Indianapolis.

FARRELL, M. (2001). Key Issues for Primary Schools. Routledge: London.

FREEMAN, M. (2014). The Future of Children's Rights. Martinus Nijhoff Publishers: Leiden.

GUTERMAN, N. (2001). Stopping Child Maltreatment Before it starts: Emerging Horizons in Early Home Visitation Services. Sage: California.

HINDS, T., \& GIARDINO, A. (2017). Child Physical Abuse: Current Evidence, Clinical Practice, and Policy Directions. Springer: Cham.

HIRSCHY, S \& WILKINSON, E. (2010). Protecting Our Children: Understanding and Preventing Abuse and Neglect in Early Childhood. Wadsworth Cengage Learning: California.

KAY, J. (2003). Protecting Children. Continuum: London.

MASH, J., \& WOLPE, D. (2016). Abnormal child psychology. Cengage learning: Boston.

MEADOWS, S. (2010). The Child as social person. Routledge: London.

MILLER- PERRIN, C., \& PERRIN, R. (2007). Child Maltreatment: An Introduction. Sage: California.

MILLER- PERRIN, C., \& PERRIN, R. (2012). Child Maltreatment: An Introduction. Sage: California.

MOKOMANE, Z. (2014). Work-Family Interface in Sub-Saharan Africa: Challenges and Responses. Springer: New York.

OFFOHIA, M., \& SADIKU, M. (1996). Ethnic and Cultural Diversity in Nigeria. African World Press: Trenton.

OKUMA, P. (2009). Omumu-the Igbo Life-value: A Challenge to Human Life Issue Today. Peter Lang: Frankfurt.

PADHI, I. (2013). Child abuse and Teenage Trauma: Girls in a Slum of Odisha, India. International Journal of Human Development and Sustainability, 6(1) 27-35.

RANYARD, R. (2017). Economic Psychology. British Psychological Society: Chichester. 
RATHUS, S. (2014). Childhood and Adolescence: Voyages in Development. Wadsworth Cengage Learning: California.

STANLEY, C. (1994). The Source of my Strength. Thomas Nelson: Dallas. UKWUOMA, A. (2014). Child marriage in Nigeria: the health hazards and socio- legal implications. Lulu Press: California. 